Archives de sciences sociales des religions

196 | octobre-décembre 2021

Bulletin bibliographique

\title{
Frédéric GUGELOT, Paul ZAWADZKI (dir.), Rire sans foi ni loi?
}

Paris, Hermann, 2021, 303 p.

\section{Claude Langlois}

\section{CpenEdition}

Journals

Édition électronique

URL : https://journals.openedition.org/assr/64694

DOI : $10.4000 /$ assr.64694

ISSN : $1777-5825$

Éditeur

Éditions de l'EHESS

Édition imprimée

Date de publication : 4 décembre 2021

Pagination : 290-292

ISBN : 9782713228735

ISSN : 0335-5985

\section{Référence électronique}

Claude Langlois, "Frédéric gugelot, Paul zawadzkı (dir.), Rire sans foi ni loi ? », Archives de sciences sociales des religions [En ligne], 196 | octobre-décembre 2021, mis en ligne le 01 décembre 2021, consulté le 13 février 2022. URL : http://journals.openedition.org/assr/64694; DOI : https://doi.org/ 10.4000/assr.64694

Ce document a été généré automatiquement le 13 février 2022.

(C) Archives de sciences sociales des religions 


\title{
Frédéric GUGELOT, Paul ZAWADZKI (dir.), Rire sans foi ni loi?
}

Paris, Hermann, 2021, 303 p.

\author{
Claude Langlois
}

\section{RÉFÉRENCE}

Frédéric GUGelot, Paul zAWADzkI (dir.), Rire sans foi ni loi ?. Paris, Hermann, 2021, 303 p.

1 Ce livre, fruit d'un colloque qui eut lieu en février 2015, un mois après les attentats que l'on sait, fut donné à l'impression en octobre 2020, au lendemain de l'assassinat de Samuel Paty. Si ces événements, ou d'autres semblables, ont été évoqués dans ce collectif et ont sans doute justifié l'ajout d'une éclairante mise au point de Jeanne Favret-Saada qui depuis plus de vingt ans s'est fait la spécialiste des affaires de blasphème, toutefois le but assigné aux universitaires sollicités était de prendre la distance avec une actualité oppressante en privilégiant des perspectives « anthropologiques, socio-historiques, philosophiques ou littéraires» (p. 12).

2 Ce décentrement a pris diverses formes. La première est la constitution d'une perspective historique en deux temps. Évocation, d'abord, de l'antiquité classique (Sparte, les dieux homériques) et juive (les rabbins de l'antiquité). Puis saut brusque et dépaysant dans le contemporain, avec les caricatures antiprotestantes de la Belle Époque, des histoires banalement drôles visant des prêtres catholiques au $\mathrm{xx}^{\mathrm{e}}$ siècle et la Prière Punk des Pussy Riot dans la Russie de Poutine en 2012, qui ne fit pas rire les représentants de l'Église orthodoxe ni ceux du pouvoir. Le volet plus proprement littéraire est représenté par l'évocation des libertins français du premier $\mathrm{XVII}^{\mathrm{e}}$, du Fado anticlérical portugais entre 1880 et 1910 et d'une étude acérée sur Jean Genet. On serait tenté $d$ 'y adjoindre une exégèse rabbinique quelque peu intemporelle d'un texte célèbre de la Genèse où Abraham et sa femme Sarah répondent par le rire quand Dieu ou ses représentants leur font savoir qu'ils auront un fils dans leur grand âge. Puis vient un judicieux détour par les rites, ce qui conduit le lecteur à des déplacements 
dans le temps (les sociétés ashkénazes $\mathrm{du} \mathrm{XVI}^{\mathrm{e}}$-XVII ${ }^{\mathrm{e}}$ siècle) et surtout dans l'espace (le choix de terrains himalayens actuels doublement explorés à travers le bouddhisme et le chamanisme). Enfin, pour nouer davantage la réflexion, deux articles plus réflexifs autour de l'humour et du rire cruel de domination introduisent à une conclusion bien venue.

3 Pointer les absences, dans ce collectif de seize communications, pourrait relever de la mauvaise foi car pareil recueil se nourrit surtout de l'hétérogénéité des sujets traités dans la mesure où ils se font écho l'un à l'autre. Ce qui est souvent le cas. J'en vois pourtant deux. D'abord la révérence obligée au Bergson du Rire n'a pas d'équivalents littéraires. Quelques évocations de Rabelais, quasiment rien de Molière ni de Voltaire, ce qui fait disparaître toute une généalogie critique dont se nourrissent les Lumières, légitimant en France un rire "quoi qu'il en coûte ». Par ailleurs, en vis-à-vis d'un judaïsme largement représenté, rien sur l'Islam. On n'y rirait donc pas ou n'y a-t-on pas été voir? Un article publié dans le même contexte des attentats de 2015 y répond en ligne avec pertinence (Mohamed Ben Mansour, « Rire en Islam », La vie des idées, Collège de France, 13 décembre 2016).

4 La réflexion première consistait donc à distinguer le rire de qui prend la religion comme objet possible de dérision du rire dans qui fait apparaître plus subtilement l'incorporation du rire dans le rapport studieux des exégètes aux textes sacrés ou dans des rituels qui, pour éviter une tension excessive des participants, glissaient des contrepoints d'autodérision comme modalités d'une respiration nécessaire. Dans ce large cadre, les différents intervenants se sont évertués à identifier les modalités innombrables du rire, de la bienveillance souriante à la cruauté glaciale, en privilégiant un humour, qui est, comme on le sait bien, la politesse du désespoir.

5 Par leur qualité formelle, ces études unissent délimitation des territoires et carte pour se déplacer de l'un à l'autre. Ainsi à la question initiale - peut-on rire des dieux et de leurs représentants? - s'est substitué rapidement une autre, plus intéressante: les dieux rient-ils et comment? Et l'évocation de l'inextinguible rire des dieux homériques a conduit à rappeler des interrogations récurrentes des théologiens catholiques au $\mathrm{XVII}^{\mathrm{e}}$ siècle sur le non-rire de Jésus. Si le rire, selon Aristote, source philosophique des scolastiques, est le propre de l'homme, comment Jésus pouvait-il être pleinement homme sans rire?

6 Reste l'arrière-plan de cet ouvrage : ce rire qui blesse le sacré, le surgissement du sacrilège et les attentats répétés. Il fallait donc restituer une généalogie mortifère, celle des caricatures de Mahomet. Septembre 2005, les douze dessins d'un journal danois dont «quatre » caricatures du Prophète, deviennent un enjeu rapidement mondialisé par le double relai des instances internationales de l'Islam et de la presse occidentale dont Charlie hebdo qui, en février 2006, les fait connaître en France. Ce qui conduisit, en janvier 2015, à l'attentat meurtrier contre ses journalistes et en octobre 2020 à l'assassinat de Samuel Paty, un enseignant qui se servait des dites caricatures pour illustrer la liberté d'expression. Hormis l'article sur la caricature antiprotestante de la fin du XIX siècle, à situer au regard des deux plus importantes, l'anti-juive et l'anti catholique, ce support spécifique n'a pas été ici exploré, sinon dans l'esquisse finale de Favret-Saada.

7 Je prendrais donc le risque d'invoquer une compétence ancienne d'historien de la caricature révolutionnaire pour prendre une modeste part à cette réflexion collective, car telle est bien l'invite d'un tel ouvrage. Résumons: liberté d'expression contre 
honneur du prophète. Pour mieux comprendre le contexte actuel, je propose une généalogie plus ancienne, celle de Hara-Kiri, du 16 novembre1970: «Bal tragique à Colombey - Un mort». Amalgame classique de deux événements proches dans le temps, la mort du général de Gaulle ( 9 novembre) et l'incendie d'une discothèque à Saint-Laurent-du-Pont en Isère le $1^{\text {er }}$ novembre qui fit 146 morts. La presse pour cette catastrophe usa abondamment de l'adjectif "tragique», ici repris. Pour la petite histoire, le journal, suspendu immédiatement par le ministre de l'Intérieur, reprend aussitôt vie sous le nom Charlie Hebdo, ce qui justifie aussi ce retour à l'après 68. En fait le "Bal tragique à Colombey» était seulement un texte étalé sur toute la une de l'hebdomadaire. Ce qui montre, pour une certaine caricature politique, la prééminence du texte, comme plus près de nous, l'affaire des pingouins de Xavier Gorce, chez qui le dessin répétitif ne sert que de support à l'impertinence des dialogues.

8 À la réflexion, une caricature sur les événements de 2015, comme celle de 1970, serait impossible présentement. D'abord parce que les familles des victimes de l'incendie auraient crié leur indignation. Mais surtout parce que personne n'aurait osé, au lendemain de l'attentat contre Charlie, s'inspirer de l'impertinence d'Hara-Kiri riant du décès de l'ancien président de la République. Les nouveaux morts sont sacrés. C'est ce qui est rappelé par Robert Badinter, célébrant Paty comme " un héros tranquille », un vrai combattant de la liberté, un enseignant qui a «tenu bon les valeurs essentielles sans lesquelles la République n'existe plus ». Depuis l'antiquité, on savait qu'on ne riait pas d'Antigone, encourant la mort pour avoir obéi à son devoir. Il existe donc bien un sacré civique qui trace une frontière invisible dont chaque événement tragique conduit à renforcer l'existence. L'admettre aiderait peut-être à comprendre qu'on ne peut en démocratie rire de tout et de tous. À quoi pourrait s'ajouter la suggestion d'une pratique prudentielle reposant sur une distinction toujours pertinente entre la jouissance d'un droit et les modalités de son usage. 